\title{
The role of stereotactic radiosurgery for low-grade astrocytomas
}

\author{
Costas G. Hadjipanayis, M.D., Douglas Kondziolka, M.D., M.Sc., \\ John C. Flickinger, M.D., AND L. DADE LunSFORD, M.D.
}

Departments of Neurological Surgery, Radiation Oncology, and the Center for Image-Guided Neurosurgery, University of Pittsburgh Medical Center, Pittsburgh, Pennsylvania

\begin{abstract}
Object. This study was conducted to examine the role of radiosurgery in the management of patients with recurrent or unresectable low-grade astrocytomas.

Methods. During a 13-year interval, 49 patients underwent stereotactic radiosurgery as part of multimodal treatment of their recurrent or unresectable low-grade astrocytomas. Thirty-seven of these patients (median age 14 years) harbored pilocytic astrocytomas and 12 patients harbored World Health Organization (WHO) Grade II fibrillary astrocytomas (median age 25 years). Tumors involved the brainstem in 22 cases, cerebellum in four, thalamus in six, temporal lobe in five, frontal lobe in four, and parietal lobe in three, as well as the hypothalamus, corpus callosum, insular cortex, optic tract, and third ventricle in one patient each. Each diagnosis was confirmed with the aid of stereotactic biopsy sampling in 17 patients, open biopsy sampling in five, partial resection in 13, and near-total resection in 14 . Multimodal treatment included fractionated radiotherapy in 14 patients, stereotactic intracavitary irradiation in five, chemotherapy in two, cyst drainage in eight, ventriculoperitoneal shunt placement in five, and additional cytoreductive surgery in five. Tumor volumes ranged from 0.42 to $45.1 \mathrm{~cm}^{3}$. The median radiosurgical dose to the tumor margin was 15 Gy (range 9.6-22.5 Gy).

After radiosurgery, serial neuroimaging demonstrated complete tumor resolution in 11 patients, reduced tumor volume in 12 , stable tumor volume in 10 , and delayed tumor progression in 16 . No procedure-related death was encountered. Forty-five of 49 patients are alive at a median follow-up period of 32 months after radiosurgery and 63 months after diagnosis. Sixteen patients participated in follow-up review for more than 60 months. Three patients died of local tumor progression.

Conclusions. Stereotactic radiosurgery is a potential alternative or adjunctive intervention in the management of selected patients with pilocytic or WHO Grade II fibrillary astrocytomas, usually performed for small-volume tumors in an attempt to avoid larger-field fractionated radiotherapy.
\end{abstract}

\section{KEY WORDS • astrocytoma • low-grade astrocytoma • pilocytic astrocytoma • fibrillary astrocytoma • gamma knife • radiosurgery}

Low-grade astrocytomas are mainly composed of WHO Grade II fibrillary and pilocytic astrocytomas. Each represents a distinct histological subtype of glial neoplasms with differences in prognosis. Pilocytic astrocytomas, frequently diagnosed in children and young adults, often behave in a comparatively indolent fashion. They are potentially curable by surgery and are associated with long survival. ${ }^{13,17,22,26,51,55}$ Grade II fibrillary astrocytomas also occur in young adults but are associated with a more aggressive clinical course characterized by a median survival of 7 to 10 years, even after aggressive treatment including surgery and radiotherapy. ${ }^{2,15,38,39,41}$ For both pilocytic and low-grade fibrillary astrocytomas, adverse location, tumor recurrence, or progression despite surgery require the provision of other treatment modalities. We have published reports detailing our experience in 37

Abbreviations used in this paper: $\mathrm{CT}=$ computerized tomography; GKS = gamma knife surgery; MR = magnetic resonance; $\mathrm{SRS}=$ stereotactic radiosurgery; $\mathrm{VP}=$ ventriculoperitoneal; $\mathrm{WHO}=$ World Health Organization . patients with pilocytic astrocytomas and 12 with Grade II fibrillary astrocytomas who underwent SRS as part of multimodal therapy. ${ }^{23,25}$ The goal of the present study was to assess the role of SRS in the management of selected patients with unresectable or recurrent low-grade astrocytomas.

\section{CLINICAL MATERIAL AND METHODS}

The medical records of 49 patients, who had undergone multimodal treatment of recurrent or critically located pilocytic and WHO Grade II fibrillary astrocytomas at the University of Pittsburgh Medical Center, were retrospectively examined. Twenty-five female and 24 male patients with either pilocytic or Grade II fibrillary astrocytomas underwent GKS. At treatment their age ranged from 3 to 68 years (median 16 years). Prior surgical intervention included near-total removal in 15 patients, partial removal in 16, an open biopsy procedure in five, and stereotactic biopsy sampling in 17. Six patients underwent multiple resections before GKS. Twenty-four patients underwent 
adjuvant SRS for lesions not amenable to complete resection. In 16 of these patients a biopsy sample was obtained and examined prior to radiosurgery, and eight underwent radiosurgery within 6 months of resection to treat residual disease. Twenty-five patients underwent SRS for recurrent tumor. Additional previous therapies included fractionated radiotherapy in 13 patients, stereotactic cyst drainage in four, and VP shunt placement in four. A summary of patient data, tumor location, and multimodal therapy before radiosurgery is presented in Table 1 . The tumor volumes ranged from 0.42 to $45.1 \mathrm{~cm}^{3}$ (median $3.3 \mathrm{~cm}^{3}$ ), and the radiation dose to the tumor margin ranged from 9.6 to 22.5 Gy (median dose 15 Gy).

TABLE 1

Clinical characteristics of 49 patients with low-grade astrocytomas

\begin{tabular}{|c|c|}
\hline Factor & No. of Patients $(\%)$ \\
\hline \multicolumn{2}{|l|}{$\operatorname{sex}$} \\
\hline male & $24(49)$ \\
\hline female & $25(51)$ \\
\hline \multicolumn{2}{|l|}{ age $(\mathrm{yrs})^{*}$} \\
\hline$\leq 18$ & $29(59)$ \\
\hline$>18$ & $20(41)$ \\
\hline \multicolumn{2}{|l|}{ tumor type $\dagger$} \\
\hline pilocytic astrocytoma & $37(76)$ \\
\hline $\begin{array}{l}\text { WHO Grade II fibrillary astrocytoma } \\
\text { solid, circumscribed }\end{array}$ & $12(24)$ \\
\hline pilocytic astrocytoma & $25(51)$ \\
\hline WHO Grade II fibrillary astrocytoma & $9(18)$ \\
\hline \multicolumn{2}{|l|}{ multifocal (diffuse) } \\
\hline pilocytic astrocytoma & $4(8)$ \\
\hline \multicolumn{2}{|l|}{ cystic } \\
\hline pilocytic astrocytoma & $8(16)$ \\
\hline Grade II fibrillary astrocytoma & $3(6)$ \\
\hline \multicolumn{2}{|l|}{ radiosurgery timing } \\
\hline adjuvant & $24(49)$ \\
\hline for recurrent tumor & $25(51)$ \\
\hline $\begin{array}{r}\text { tumor location } \\
\text { infratentorial } \\
\text { brainstem }\end{array}$ & \\
\hline midbrain & $9(18)$ \\
\hline pons & $8(16)$ \\
\hline cerebellar peduncle & $4(8)$ \\
\hline \multicolumn{2}{|l|}{ cerebellum } \\
\hline hemisphere & $2(4)$ \\
\hline vermis & $2(4)$ \\
\hline \multicolumn{2}{|l|}{ supratentorial } \\
\hline thalamus & $6(12)$ \\
\hline temporal lobe (medial) & $5(10)$ \\
\hline parietal lobe & $3(6)$ \\
\hline 3rd ventricle & $1(2)$ \\
\hline optic tract & $1(2)$ \\
\hline hypothalamus & $1(2)$ \\
\hline corpus callosum & $1(2)$ \\
\hline insular cortex & $1(2)$ \\
\hline \multicolumn{2}{|l|}{$\begin{array}{l}\text { prior treatment modality } \\
\text { resection }\end{array}$} \\
\hline near-total & $15(31)$ \\
\hline partial & $16(33)$ \\
\hline multiple & $6(12)$ \\
\hline fractionated radiotherapy & $13(27)$ \\
\hline stereotactic cyst drainage & $4(8)$ \\
\hline VP shunt placement & $4(8)$ \\
\hline
\end{tabular}

* The median age was 18 (range 3-38 years).

$\dagger$ The median tumor volume was $3.3 \mathrm{~cm}^{3}$ (range $0.42-45.1 \mathrm{~cm}^{3}$ ).
The diagnosis of pilocytic or Grade II fibrillary astrocytoma was confirmed with the aid of stereotactic biopsy sampling in 17 patients, open biopsy sampling in five, partial resection in 13, and near-total resection in 14. Analysis of tumor control was stratified according to whether the tumor was cystic, solid and circumscribed, or multifocal (diffuse). In total, 34 patients harbored solid and circumscribed pilocytic astrocytomas (25 cases) and Grade II fibrillary astrocytomas (nine cases) (Table 1). In the group of patients in whom GKS was performed as an adjuvant therapy, 17 harbored tumors that were solid and circumscribed and seven harbored cystic tumors. Of patients with GKStreated recurrent tumors, 17 harbored solid and circumscribed tumors, four cystic tumors, and four multifocal tumors. All patients in this study presented for radiosurgery after evaluation of an initial biopsy sample or attempted resection. Gamma knife surgery was performed as an adjunct to stereotactic biopsy, stereotactic cyst aspiration, open biopsy sampling, or resection, or as a treatment for recurrent tumors after resection. In many patients, radiosurgery was conducted as an alternative to larger-field fractionated radiotherapy.

Radiosurgical treatment began with rigid fixation of an imaging-compatible Leksell stereotactic frame (model G; Elekta Instruments, Atlanta, GA) to the patient's head. Regional anesthetic scalp infiltration (5\% marcaine and $1 \%$ xylocaine buffered with sodium bicarbonate) and mild sedation were used. General anesthesia was induced in children younger than 12 years of age. Stereotactic CT scanning was used for target localization and planning prior to 1993, after which we used MR imaging because of its better image resolution, superior tissue contrast, and virtually artifact-free visualization. After 1993, CT scanning was performed only if MR imaging was contraindicated because of metal implants in the body. High-resolution Gd-enhanced $\mathrm{T}_{1}$-weighted sagittal scout MR images were obtained first to localize the area of interest. To define the radiosurgical target volume, multiplanar volume-acquisition contrast-enhanced MR images (divided into 28-60 axial slices of 1-mm thickness) were acquired. All of the pilocytic astrocytomas enhanced after administration of contrast on CT scanning or MR imaging. Patients with Grade II fibrillary astrocytomas additionally underwent long-repetition time MR imaging to delineate better any edema from nonenhancing tumor tissue. These images were transported via fiberoptic ethernet to a highspeed computer workstation for gamma knife treatment planning. The planning was performed on axial images supplemented by coronal and sagittal reformatted images. A conformal plan was achieved using multiple isocenters of different diameters. The treatment volume for pilocytic astrocytomas consisted of the enhancing component of the tumor and cyst wall if present. For Grade II fibrillary astrocytomas, the treatment volume consisted of the nonenhancing tumor tissue. After finalizing the plan, a maximum margin dose was determined. The treatment isodose, maximum dose, and margin dose were jointly decided by a neurosurgeon, radiation oncologist, and medical physicist. The dose was selected based on tumor volume, location, and estimated tolerance of nearby critical structures, especially if prior fractionated radiotherapy had been administered. Radiosurgery was performed with a 201source, ${ }^{60} \mathrm{Co}$ Leksell gamma knife (Model U or Model B; 
Elekta Instruments) by positioning the target serially at $\mathrm{x}$, $\mathrm{y}$, and $\mathrm{z}$ coordinates of each isocenter. All patients received a 10- to 40-mg dose of methylprednisolone at the conclusion of the procedure. The stereotactic frame was removed immediately afterwards, and patients were discharged within the next 6 to 18 hours.

All patients underwent serial follow-up imaging studies (usually MR imaging), which were requested at 3-, 6-, 12, and 24-month intervals if no tumor growth was noted. In case of neurological deterioration, interval images were obtained. If there was no appreciable change in tumor size, subsequent MR images were requested at 1-year intervals. Patients who lived a long distance from Pittsburgh were evaluated by their referring physician who forwarded the imaging and clinical data to the Center for ImageGuided Neurosurgery at the University of Pittsburgh. Patients or their families were also contacted by telephone to optimize the follow-up data.

\section{RESULTS}

\section{Clinical Outcomes}

Forty-five (92\%) of 49 patients are alive at a median follow-up length of 32 months after radiosurgery (range 3-159 months) and 63 months after diagnosis (range 2-186 months). Procedure-related permanent morbidity or mortality did not occur in this series. In one patient the Karnofsky Performance Scale score was 30; otherwise, in all surviving patients in this study scores ranged from 80 to 100 as of last follow-up examination. Three patients died of local tumor progression 23, 72, and 115 months after diagnosis, respectively, and 7, 71, and 29 months after GKS. One patient died of respiratory failure caused by pneumonia unrelated to brain tumor.

\section{Adverse Effects of Radiation}

Two patients experienced a temporary worsening of their neurological conditions after radiosurgery. Magnetic resonance imaging revealed increased contrast enhancement of the tumor associated with $\mathrm{T}_{2}$-weighted sequence changes of the surrounding brain. One patient suffered a deterioration in speech 6 months after radiosurgery and 12 months after fractionated radiation therapy. Staff at an outside institution believed tumor recurrence had developed, and the patient received steroid therapy and was started on a new chemotherapeutic regimen (ifosfamide, carboplatin, and etoposide). We believe the imaging-related changes associated with the patient's clinical deterioration were due to radiation effect, not tumor recurrence. On followup imaging 24 months after radiosurgery, there was decreased enhancement and $\mathrm{T}_{2}$-weighted change associated with the tumor. The patient exhibited no expressive aphasia at last clinical follow up. The other patient experienced slight worsening of his hemiparesis 7 months after radiosurgery, which eventually improved. By 28 months after radiosurgery, greater than $50 \%$ reduction in size of his tumor had been achieved.

\section{Imaging Results}

Follow-up imaging studies demonstrated tumor control in $33(67 \%)$ of 49 patients. Complete resolution was iden- tified in 11 patients and reduction in tumor volume in 12 patients. In ten patients the appearance of the tumor remained unchanged after radiosurgery. In 16 patients (33\%) delayed tumor growth was observed; in eight of these patients there was an increase in cyst size only (Tables 2 and 3).

Tumor control was achieved in $17(71 \%)$ of 24 patients in whom radiosurgery was performed as an adjuvant and in $16(64 \%)$ of 25 patients with recurrent tumors. In the adjuvant setting, complete resolution of the tumor was confirmed in six patients, reduction in tumor size in six patients, and no change in tumor size in five patients. In seven other patients $(29 \%)$ local tumor progression was identified on follow-up images. In four patients there was an increase in cyst size only. One patient died of local tumor progression 71 months after radiosurgery. Among patients with GKS-treated recurrent tumors, complete resolution was documented in five patients, reduction in tumor size in six, and no change in tumor size in five. In nine patients (36\%) local tumor progression was noted on follow-up images, in four of whom there was an increase in cyst size only. Two patients died of local tumor progression 7 and 29 months, respectively, after radiosurgery.

Tumor control was achieved in $29(85 \%)$ of 34 patients with solid, circumscribed tumors and was verified with the aid of images obtained after radiosurgery (Fig. 1). In nine patients complete resolution of tumor was demonstrated on follow-up images; in 11 patients a reduction in tumor size was observed; in nine patients there was no change in tumor size; and in five (15\%) local tumor progression was identified. Local tumor progression was exhibited in three of four patients who harbored multifocal tumors according to follow-up data; two of these patients died. In eight of 11 patients with cystic tumors there was an increase only in cyst size after radiosurgery.

\section{Low-Grade Astrocytomas Located in the Brainstem}

Progressive lesions were located in the brainstem in 22 patients. In $15(68 \%)$ of these patients the lesions were solid, circumscribed tumors; in three (14\%) they were cystic; and in four patients $(18 \%)$ they were multifocal. Tumor control was achieved in $13(59 \%)$ of 22 patients after radiosurgery. In four patients there was complete resolution, in six there was a decrease in tumor size, and in three the tumor size was stable after radiosurgery. Follow-up imaging demonstrated tumor progression in nine patients $(41 \%)$. Two patients underwent additional cytoreductive surgery. Three patients died of local tumor progression.

Twelve patients with tumors located in the brainstem

TABLE 2

\begin{tabular}{cc} 
Imaging-documented tumor response after radiosurgery \\
\hline Tumor Response & No. of Cases (\%) \\
\hline regression & $23(47)$ \\
complete resolution & $11(22)$ \\
volume reduction & $12(24)$ \\
unchanged & $10(20)$ \\
progression & $16(33)$ \\
cyst increase only & $8(16)$ \\
\hline
\end{tabular}




\section{G. Hadjipanayis, et al.}

TABLE 3

Imaging-documented tumor type and response after radiosurgery

\begin{tabular}{lccccc}
\hline \hline \multicolumn{1}{c}{ Tumor Type } & $\begin{array}{c}\text { No. of } \\
\text { Lesions }\end{array}$ & $\begin{array}{c}\text { Complete } \\
\text { Reso- } \\
\text { lution }\end{array}$ & $\begin{array}{c}\text { Volume } \\
\text { Re- } \\
\text { duction }\end{array}$ & $\begin{array}{c}\text { Un- } \\
\text { changed }\end{array}$ & $\begin{array}{c}\text { Tumor } \\
\text { Pro- } \\
\text { gression }\end{array}$ \\
\hline solid, circumscribed & 34 & 9 & 11 & 9 & 5 \\
multifocal & 4 & 1 & 0 & 0 & 3 \\
cystic & 11 & 1 & 1 & 1 & 8 \\
\hline
\end{tabular}

underwent adjuvant radiosurgery. In eight $(67 \%)$ tumor control was achieved after radiosurgery, and in four (33\%) there was evidence of tumor progression on follow-up images. In three of the latter there was an increase in cyst size only. Ten patients underwent GKS for recurrent tumors located in the brainstem. In five patients (50\%) tumor control was achieved, and in five others (50\%) tumor progression was evident on follow-up images.

\section{Biopsy Procedure Followed by Radiosurgery}

In this series, 16 patients underwent biopsy sampling, performed by open surgery in three patients or stereotactically in 13, before they underwent radiosurgery (Fig. 2). The location of these tumors included the brainstem in eight patients, the parietal lobe in three, the thalamus in two, and the frontal lobe (periventricular), temporal lobe (medial), and third ventricle in one patient each. These patients had not undergone previous tumor resection. Two patients with Grade II fibrillary astrocytomas underwent fractionated radiotherapy prior to GKS. One patient underwent placement of a VP shunt, and one patient underwent two stereotactic cyst aspirations prior to GKS. Two patients underwent additional therapy after radiosurgery: fractionated radiotherapy 9 months following radiosurgery at another institution in one patient with worsening hemiparesis and stereotactic cyst drainage in the second patient due to cyst progression.

In $12(75 \%)$ of 16 patients tumor control was achieved by the last follow-up examination. In five patients complete resolution of tumor was confirmed on follow-up images. Follow-up imaging demonstrated a reduction in tumor size in four patients and stable tumor size in four patients. Tumor progression was identified in four patients $(25 \%)$. One patient died of local tumor progression.

\section{Treatment After Radiosurgery}

Among the 16 patients in whom there was delayed tumor growth, five required additional cytoreductive surgery. In one patient with a Grade II fibrillary astrocytoma there was solid tumor progression, which on microscopic examination was shown to be anaplastic astrocytoma. In eight patients there was only an increase in tumor cyst size. Five patients underwent stereotactic cyst drainage. One patient underwent stereotactic intracavitary ${ }^{32} \mathrm{P}$ irradiation. Two patients with cyst progression have not undergone any additional procedure after radiosurgery but may require future stereotactic cyst aspiration. One patient underwent repeated GKS. Other treatments following radiosurgery included stereotactic intracavitary irradiation in four, chemotherapy in two, and fractionated radiotherapy and VP shunt placement in one patient each.
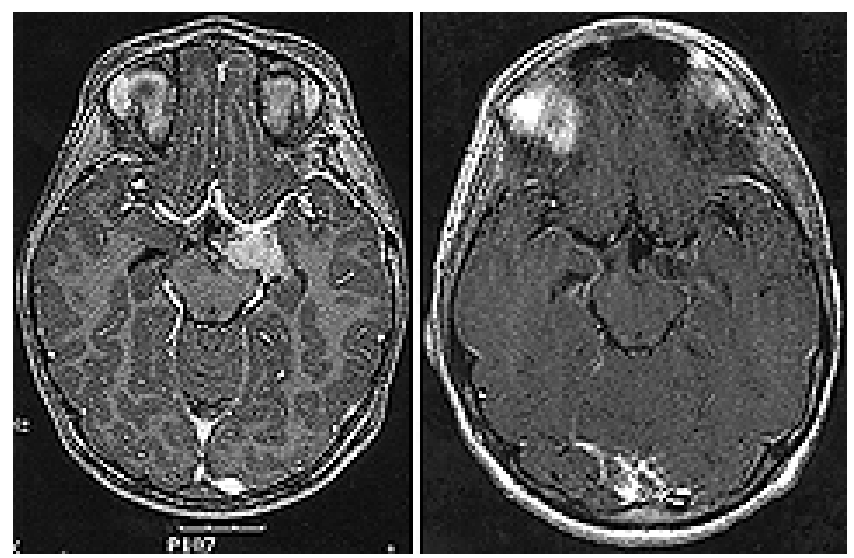

Fig. 1. Axial Gd-enhanced MR images obtained in a 6-year-old boy. Left: Image demonstrating a solid, circumscribed left optic tract pilocytic astrocytoma at the time of radiosurgery, after the patient had undergone a partial resection 4 months previously. Right: Image obtained 49 months after radiosurgery revealing significant reduction in tumor size.

\section{DISCUSSION}

\section{Treatment Modalities}

The potential role of radiosurgery for patients with selected low-grade astrocytomas has yet to be defined. Whenever possible, symptomatic or progressive pilocytic astrocytomas should be resected completely. ${ }^{10,19,21,28,30}$ Even after partial removal of the tumor, patients with pilocytic astrocytomas can undergo observation involving periodic imaging examinations before additional surgery or other treatment modalities need to be performed. ${ }^{3,4}$ For those patients in whom total or subtotal resection cannot be safely performed, radiotherapy and/or chemotherapy have often been recommended., ${ }^{9,10,18,20,22,44-46}$ Although better disease-free survival has been reported in radiotherapy or chemotherapy series, significant adverse effects on patients have been associated with these two treatment modalities. Adverse effects of cerebral irradiation include memory impairment, learning disabilities, progressive deterioration in intelligence, endocrinopathies, and malignant transformation of tumors. . $^{5,8,11,12,14,16,49}$ Chemotherapy can cause significant systemic toxicity. ${ }^{44}$ Radiosurgery has been considered as a primary alternative to radiotherapy.

Management of Grade II fibrillary astrocytomas is controversial, and practice parameters are ill defined. $.^{24,31} \mathrm{Cy}-$ toreductive surgery is indicated to relieve the symptoms of raised intracranial pressure secondary to tumor mass effect. Complete resection of these tumors is rarely possible because by nature they are infiltrative. Some authors have reported the extent of excision as a prognostic variable, but this has not been confirmed in other studies in which multivariate analysis has been conducted. $6,7,27,29,31,36,40,47$ Nevertheless, tissue diagnosis of these tumors needs to be performed either by stereotactic biopsy sampling or resection. Many of these tumors gradually transform from a slower growth rate with a lower mitotic index to an anaplastic form with a higher mitotic index..$^{1,2,15}$ In previously published studies investigators have defined the benefit of fractionated external-beam radiotherapy as an adjuvant in the management of patients who 

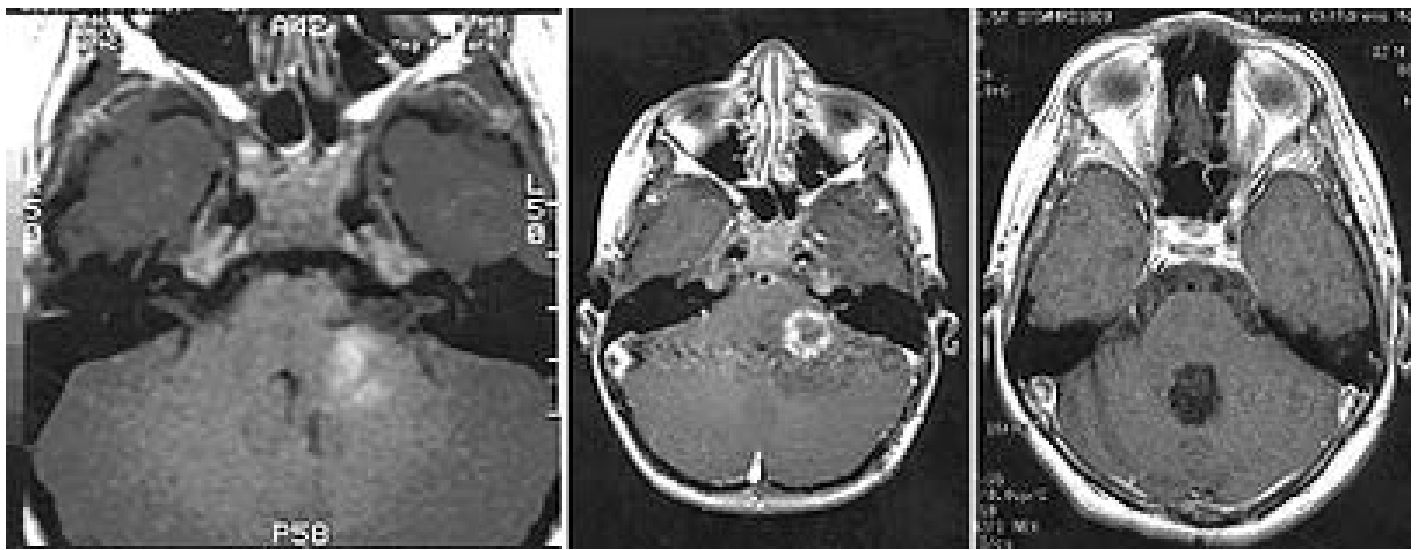

Fig. 2. Axial Gd-enhanced MR images obtained in a 4-year-old boy. Left: Image revealing a solid, circumscribed left middle cerebellar pilocytic astrocytoma confirmed histologically after the patient underwent open biopsy sampling. Center: Image obtained 4 months after radiosurgery demonstrating central tumor necrosis. Right: Image obtained 11 years after radiosurgery demonstrating complete resolution of the tumor.

underwent either biopsy sampling or cytoreductive surgery for Grade II fibrillary astrocytoma. ${ }^{6,35,37,43,48,50,52} \mathrm{In}$ patients with long-term survival after fractionated brain irradiation there is the risk developing radiation-induced late-onset leukoencephalopathy and cognitive impairment. $42,53,54$

\section{Role of Radiosurgery}

For brain tumors, the efficacy of conventional fractionated radiotherapy is dependent on the differential biological sensitivity of normal and tumor cells to radiation. Growth kinetics of pilocytic and Grade II astrocytomas make the radiosensitivity of normal cells and neoplasm very similar. Because of its capability to deliver a high radiation dose to tumor with a sharp falloff to normal surrounding tissue, radiosurgery is not limited by the biological differential sensitivity of tumor and normal cells. The goal of radiosurgery is to arrest the cell-division capability of target cells irrespective of the individual cell's mitotic activity and radiosensitivity. Radiosurgery also allows for delayed intratumoral vascular obliteration. In the treatment of cases involving the developing nervous system, the opportunity to use focused radiation to the lesion represents an attractive treatment alternative that may reduce the potential long-term risks of cognitive or endocrinological dysfunction associated with fractionated radiation therapy. ${ }^{34}$ Additionally SRS also eliminates the potential systemic toxicity observed with chemotherapy.

The majority of radiosurgery studies have focused on the treatment of malignant gliomas. We could only find one published series by Kida, et al., ${ }^{32}$ on radiosurgery for low-grade astrocytomas that included 39 patients with Grade II astrocytomas and 12 patients with pilocytic astrocytomas. These authors treated patients using a median margin dose of 15.7 Gy for Grade II astrocytomas and 12.5 Gy for pilocytic astrocytomas. Tumor response (regression) and control rates of 46.2 and $87.2 \%$, respectively, for Grade II astrocytomas, and 50 and $91.7 \%$, respectively, for pilocytic astrocytomas were achieved. Radiation-induced edema was noted in $35 \%$ of the patients and close to $50 \%$ of these were symptomatic requiring steroid administration. These authors also noted cyst formation and temporary tumor swelling (7.7\%) after radiosurgery.

Patients with progressive, pilocytic, or Grade II fibrillary astrocytomas, located in critical or deep areas of the brain, are ideal candidates for radiosurgery. In our series of 49 patients, tumor control was achieved in $33(67 \%)$. For patients with solid, circumscribed tumors the disease control rate was $85 \%$. Radiosurgery was performed as part of multimodal therapy in the majority of patients in the series. No permanent complications occurred following radiosurgery, and all 45 patients who remain alive are without cognitive or endocrinological deficits.

We have shown in the past that SRS for intraparenchymal brainstem tumors can be performed safely. ${ }^{33}$ In our series 22 patients harbored progressive lesions located in the brainstem. In 13 patients (59\%) tumor control was achieved after radiosurgery. No patient with a brainstem lesion suffered any procedure-related morbidity or mortality after SRS.

\section{Biopsy Procedure Followed by SRS}

A biopsy procedure followed by radiosurgery of histologically proven pilocytic or Grade II fibrillary astrocytoma is a potential treatment alternative in patients with solid, circumscribed tumors who do not undergo resection. In this series, 16 patients underwent biopsy sampling and subsequent radiosurgery. Tumor control was achieved in $75 \%$. The majority (69\%) of these lesions were solid, circumscribed tumors.

\section{The Risks of Radiosurgery}

The two patients believed to have experienced adverse radiation-induced effects after radiosurgery both exhibited improvement in clinical condition and imaging-documented tumor characteristics 24 and 28 months, respectively, after GKS.

\section{CONCLUSIONS}

The use of SRS as part of multimodal therapy for pro- 
gressive, recurrent, or unresectable pilocytic or WHO Grade II fibrillary astrocytomas is a safe and promising therapeutic modality.

\section{References}

1. Afra D, Osztie E: Histologically confirmed changes on CT of reoperated low-grade astrocytomas. Neuroradiology 39: 804-810, 1997

2. Afra D, Osztie E, Sipos L, et al: Preoperative history and postoperative survival of supratentorial low-grade astrocytomas. Br J Neurosurg 13:299-305, 1999

3. Alpers CE, Davis RL, Wilson CB: Persistence and late malignant transformation of childhood cerebellar astrocytoma. Case report. J Neurosurg 57:548-551, 1982

4. Austin EJ, Alvord EC Jr: Recurrences of cerebellar astrocytomas: a violation of Collins' law. J Neurosurg 68:41-47, 1988

5. Bajorunas DR, Ghavimi F, Jereb B, et al: Endocrine sequelae of antineoplastic therapy in childhood head and neck malignancies. J Clin Endocrinol Metab 50:329-335, 1980

6. Bauman G, Lote K, Larson D, et al: Pretreatment factors predict overall survival for patients with low-grade glioma: a recursive partitioning analysis. Int J Radiat Oncol Biol Phys 45: 923-929, 1999

7. Berger MS, Deliganis AV, Dobbins J, et al: The effect of extent of resection on recurrence in patients with low grade cerebral hemisphere gliomas. Cancer 74:1784-1791, 1994

8. Bernell WR, Kepes JJ, Seitz EP: Late malignant recurrence of childhood cerebellar astrocytoma. Report of two cases. J Neurosurg 37:470-474, 1972

9. Brown MT, Friedman HS, Oakes J, et al: Chemotherapy for pilocytic astrocytomas. Cancer 71:3165-3172, 1993

10. Bucy PC, Thieman PW: Astrocytomas of the cerebellum. A study of a series of patients operated upon over 28 years ago. Arch Neurol 18:14-19, 1968

11. Budka H: Partially resected and irradiated cerebellar astrocytoma of childhood: malignant evolution after 28 years. Acta Neurochir 32:139-146, 1975

12. Constine LS, Woolf PD, Cann D, et al: Hypothalamic-pituitary dysfunction after radiation for brain tumors. N Engl J Med 328:87-94, 1993

13. Conway PD, Oechler HW, Kun LE, et al: Importance of histologic condition and treatment of pediatric cerebellar astrocytoma. Cancer 67:2772-2775, 1991

14. Dirks PB, Jay V, Becker LE, et al: Development of anaplastic changes in low-grade astrocytomas of childhood. Neurosurgery 34:68-78, 1994

15. Dropcho EJ, Soong SJ: The prognostic impact of prior low grade histology in patients with anaplastic gliomas: a case-control study. Neurology 47:684-690, 1996

16. Duffner PK, Cohen ME, Thomas PR, et al: The long-term effects of cranial irradiation on the central nervous system. Cancer (Suppl 7) 56:1841-1846, 1985

17. Forsyth PA, Shaw EG, Scheithauer BW, et al: Supratentorial pilocytic astrocytomas. A clinicopathologic, prognostic, and flow cytometric study of 51 patients. Cancer 72:1335-1342, 1993

18. Freeman CR, Farmer JP, Montes J: Low-grade astrocytomas in children: evolving management strategies. Int J Radiat Oncol Biol Phys 41:979-987, 1998

19. Garcia DM, Fulling KH: Juvenile pilocytic astrocytoma of the cerebrum in adults. A distinctive neoplasm with favorable prognosis. J Neurosurg 63:382-386, 1985

20. Garcia DM, Marks JE, Lafiti HR, et al: Childhood cerebellar astrocytomas: is there a role for postoperative irradiation? Int J Radiat Oncol Biol Phys 18:815-818, 1990

21. Geissinger JD: Astrocytomas of the cerebellum in children. Long-term study. Arch Neurol 24:125-135, 1971

22. Gjerris F, Klinken L: Long-term prognosis in children with benign cerebellar astrocytoma. J Neurosurg 49:179-184, 1978
23. Hadjipanayis CG, Kondziolka D, Gardner P, et al: Stereotactic radiosurgery for pilocytic astrocytomas when multimodal therapy is necessary. J Neurosurg 97:56-64, 2002

24. Hadjipanayis CG, Lunsford LD: Low-grade fibrillary astrocytomas. Contemp Neurosurg 23 (21): 1-5, 2001

25. Hadjipanayis CG, Niranjan A, Tyler-Kabara E, et al: Stereotactic radiosurgery for well-circumscribed fibrillary grade II astrocytomas: an initial experience. Stereotact Funct Neurosurg 79:13-24, 2002

26. Hayostek CJ, Shaw EG, Scheithauer B, et al: Astrocytomas of the cerebellum. A comparative clinicopathologic study of pilocytic and diffuse astrocytomas. Cancer 72:856-869, 1993

27. Hirano H, Asakura T, Yokoyama S: [The prognostic factors in astrocytic tumors: analysis by the Kaplan-Meier method and the Weibull log-linear model.] No Shinkei Geka 24:809-815, 1996 (Jpn)

28. Ilgren EB, Stiller CA: Cerebellar astrocytomas: therapeutic management. Acta Neurochir 81:11-26, 1986

29. Janny P, Cure H, Mohr M, et al: Low grade supratentorial astrocytomas. Management and prognostic factors. Cancer 73: 1937-1945, 1994

30. Kehler U, Arnold H, Muller H: Long-term follow-up of infratentorial pilocytic astrocytomas. Neurosurg Rev 13:315-320, 1990

31. Keles GE, Lamborn KR, Berger MS: Low-grade hemispheric gliomas in adults: a critical review of extent of resection as a factor influencing outcome. J Neurosurg 95:735-745, 2001

32. Kida Y, Kobayashi T, Mori Y: Gamma knife radiosurgery for low-grade astrocytomas: results of long-term follow up. J Neurosurg (Suppl 3) 93:42-46, 2000

33. Kondziolka D, Lunsford LD, Flickinger JC: Intraparenchymal brainstem radiosurgery. Neurosurg Clin N Am 4:469-479, 1993

34. Kondziolka D, Lunsford LD, Flickinger JC: Stereotactic radiosurgery in children and adolescents. Pedatr Neurosurg 16: 219-221, 1991

35. Landy HJ, Schwade JG, Houdek PV, et al: Long-term followup of gliomas treated with fractionated stereotactic irradiation. Acta Neurochir Suppl 62:67-71, 1994

36. Laws ER Jr, Taylor WF, Clifton MB, et al: Neurosurgical management of low-grade astrocytoma of the cerebral hemispheres. J Neurosurg 61:665-73, 1984

37. Leibel SA, Sheline GE, Wara WM, et al: The role of radiation therapy in the treatment of astrocytomas. Cancer 35: 1551-1557, 1975

38. Lunsford LD, Somaza S, Kondziolka D, et al: Brain astrocytomas: biopsy, then irradiation. Clin Neurosurg 42:464-479, 1995

39. Lunsford LD, Somaza S, Kondziolka D, et al: Survival after stereotactic biopsy and irradiation of cerebral nonanaplastic, nonpilocytic astrocytoma. J Neurosurg 82:523-529, 1995

40. Matsumoto K, Abe T, Terada K, et al: [Clinical results of supratentorial astrocytoma grade II.] No Shinkei Geka 27:139-145, 1999 (Jpn)

41. McCormack BM, Miller DC, Budzilovich GN, et al: Treatment and survival of low-grade astrocytoma in adults-1977-1988. Neurosurgery 31:636-642, 1992

42. Mulhern RK, Ochs J, Kun LE: Changes in intellect associated with cranial radiation therapy, in Gutin PH, Leibel SA, Sheline GE, (eds): Radiation Injury to The Nervous System. New York: Raven Press, 1991, pp 325-340

43. Nakamura M, Konishi N, Tsunoda S, et al: Analysis of prognostic and survival factors related to treatment of low-grade astrocytomas in adults. Oncology 58:108-116, 2000

44. Packer RJ, Lange B, Ater J, et al: Carboplatin and vincristine for recurrent and newly diagnosed low-grade gliomas of childhood. J Clin Oncol 11:850-856, 1993

45. Packer RJ, Sutton LN, Atkins TE, et al: A prospective study of cognitive function in children receiving whole brain radio- 
therapy and chemotherapy: 2-year results. J Neurosurg 70: 707-713, 1989

46. Packer RJ, Sutton LN, Bilaniuk LT, et al: Treatment of chiasmatic/hypothalamic gliomas of childhood with chemotherapy: an update. Ann Neurol 23:79-85, 1988

47. Peraud A, Ansari H, Bise K, et al: Clinical outcome of supratentorial astrocytoma WHO grade II. Acta Neurochir 140: 1213-1222, 1998

48. Salazar OM, Rubin P, McDonald JV, et al: Patterns of failure in intracranial astrocytomas after irradiation: analysis of dose and field factors. AJR 126:279-292, 1976

49. Samaan NA, Vieto R, Schultz PN, et al: Hypothalamic, pituitary and thyroid dysfunction after radiotherapy to the head and neck. Int J Radiat Oncol Biol Phys 8:1857-1867, 1982

50. Scanlon PW, Taylor WF: Radiotherapy of intracranial astrocytomas: analysis of 417 cases treated from 1960 through 1969. Neurosurgery 5:301-308, 1979

51. Sgouros S, Fineron PW, Hockley AD: Cerebellar astrocytoma of childhood: long-term follow-up. Childs Nerv Syst 11: 89-96, 1995
52. Shaw EG: The low-grade glioma debate: evidence defending the position of early radiation therapy. Clin Neurosurg 42: 488-494, 1995

53. Surma-aho O, Niemela M, Vilkki J, et al: Adverse long-term effects of brain radiotherapy in adult low-grade glioma patients. Neurology 56:1285-1290, 2001

54. Taphoorn MJ, Schiphorst AK, Snoek FJ, et al: Cognitive functions and quality of life in patients with low-grade gliomas: the impact of radiotherapy. Ann Neurol 36:48-54, 1994

55. Wallner KE, Gonzales MF, Edwards MS, et al: Treatment results of juvenile pilocytic astrocytoma. J Neurosurg 69: 171-176, 1988

Manuscript received March 17, 2003.

Accepted in final form April 14, 2003.

Address reprint requests to: Costas G. Hadjipanayis, M.D., University of Pittsburgh Medical Center-Presbyterian, Suite B-400, 200 Lothrop Street, Pittsburgh, Pennsylvania 15213. email: Costas111@pol.net. 